\title{
Bioclimatic building regulations for warm-dry climates
}

\author{
J. M. Ochoa ${ }^{1}$, A. Duarte ${ }^{1}$, I. Marincic ${ }^{1}$, A. Gomez ${ }^{2}$ \& A. Figueroa ${ }^{3}$ \\ ${ }^{I}$ Department of Architecture and Design, University of Sonora, Mexico \\ ${ }^{2}$ University of Colima, Mexico \\ ${ }^{3}$ Autonomous Metropolitan University, Mexico
}

\begin{abstract}
In Mexico, regulations on energy efficiency in buildings are in the early stages and have been poorly mixed among the different actors involved in the building processes. This situation results in the fact that economically disadvantaged people cannot have access to comfortable and energy efficient environments. This problem becomes worse in the northern regions of the country, which require air conditioning, because of the dry warm climate, for several months of the year.

A proposal of a technical standard about bioclimatic buildings for warm-dry climates is presented in this paper. Also, the process for its development is described. This involves monitoring and analysis of typical dwellings in Hermosillo city in northwest México, a hot-dry climate location.

The proposed regulation aims to reduce the environmental impact of the construction industry and energy use in buildings, by incorporating mandatory, optional and incentivized requirements to improve energy efficiency and the building's habitability. The proposal develops a set of articulated provisions in three main areas: efficient energy use; environmental comfort; vegetation with low water consumption in urban areas.

It is intended that these regulations will apply to all new buildings, expansions and major refurbishments, once they have been incorporated into municipal regulations.
\end{abstract}

Keywords: bioclimatic architecture, warm-dry climate building, energy efficiency, bioclimatic regulations. 


\section{Introduction}

Currently in the field of architecture and urbanism in Mexico, there are large gaps in rules and regulations, especially on the issue of energy efficiency and environmental comfort in buildings appropriate for each climate region.

Progress in technology of environmental conditioning enables architects to have the freedom to follow trends and construction practices of other cultures and places, often without considering any adaptation to the climate of the site, and ignoring regional building and design practices, even in the extreme hot-dry northern climates of Mexico.

The consequence is that there is no responsibility of architects to maintain comfort conditions inside the buildings, leaving all the work to artificial environmental conditioning systems, which as sophisticated, efficient or "smart" as they are, do not always meet their goal, and additionally generate very high energy consumption.

In 2009 Bioclimatic Architecture Network (BAN) was established based on the convoking of the Secretariat for Higher Education of Mexico for the formation of Thematic Academic Networks. The BAN constituted three groups of specialized research in the area of bioclimatic architecture: University of Colima, Atzcapotzalco Autonomous Metropolitan University and the University of Sonora.

The network aims to advance in the generation and application of knowledge in areas such as habitability and energy efficiency in buildings and their regulatory aspects from the perspective of bioclimatic architecture.

The BAN worked on the project: "Norms and regulations for Bioclimatic Architecture", whose main objective is the proposed regulation described in this paper.

\section{Methodology}

As a first step an analysis of current regulations and their possible effects on the activity of design and construction of buildings preferably in areas with a hot climate was performed.

Also consultations and surveys were carried out to users, building professionals, authorities and academics about knowledge of the regulations and good practices of bioclimatic construction.

A field study was conducted to find out the local construction practices and systems that enable climate adaptation. The study tried to cover various types of selected homes, both contemporary and traditional style houses. Case studies were monitored and analysed according to international standards.

Finally, a bioclimatic analysis was conducted to define the criteria and design guidelines. 


\section{Case study location and climate}

The standard was created using the example of the city of Hermosillo as a location of a hot-dry climate.

\subsection{The climate of Hermosillo}

The city is the capital of the state of Sonora. It is located in the north-western zone of Mexico, $275 \mathrm{~km}$ South of the U.S. border and 2,037 km from Mexico City, at $29^{\circ} 05^{\prime}$ North latitude.

High solar radiation levels, clear skies and daily and annual high temperature swings are typical of the local climate.

The maximum air temperature exceeds $38^{\circ} \mathrm{C}$ on an average of 90 days of the year, including most days from early June until early September, with minimum air temperatures of $20-25^{\circ} \mathrm{C}$ and maximum about $40-44^{\circ} \mathrm{C}$. Air temperatures, in extreme cases, can reach up to $50^{\circ} \mathrm{C}$. Average relative humidity oscillates between 50 and 15\%; however, the arrival of moist air in August makes it feel a little bit humid (Figure 1).

The warm season extends for 5 or 6 months per year, and the use of airconditioning is necessary inside buildings during this period.

Winters are comfortable, with minimum temperatures of $4-7^{\circ} \mathrm{C}$ and maximum between 25 and $30^{\circ} \mathrm{C}$. The city has almost 300 sunny days per year; in spring and summer, solar radiation can rise up to $1000 \mathrm{~W} / \mathrm{m}^{2}$.

The rainfall is scarce; with an annual total precipitation of $225 \mathrm{~mm}$. August is the wettest month of the year $(27 \mathrm{~mm})$.

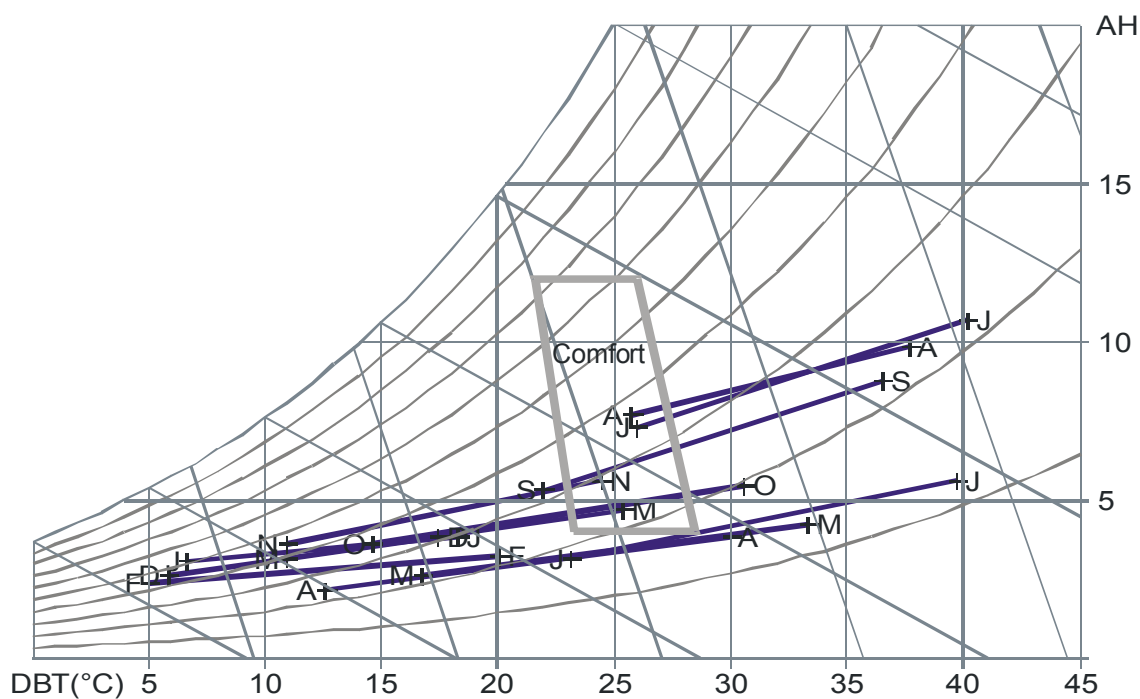

Figure 1: Maximum and minimum monthly average temperature and relative humidity of the site, plotted on the psychometric chart. 


\subsection{Urban environment and housing}

Despite the harsh environmental conditions, the new areas of the city are neither planned well nor prepared for the hot-dry desert climate. This situation contrasts with the historic old town, which consists of narrow streets, plenty of adobe houses with small windows, vegetated central patios, arcades and light colours.

Recently developed districts have wide streets, large paved areas, and detached buildings. New housing developments, even economic or high-income houses are designed with the same criteria for the mild climate of central regions of Mexico; as a consequence, there is a huge energy consumption during the warm period.

For the study, 25 model homes, representing $21 \%$ of the new homes available for sale in the city during 2011 were analysed. The constructed area of the house goes from 21 to $120 \mathrm{~m}^{2}$, the most repetitive pattern $(71 \%)$ have an area between 45 and $60 \mathrm{~m}^{2}$, and it's known as "minimum housing". Figure 2 shows some facades of minimum houses.

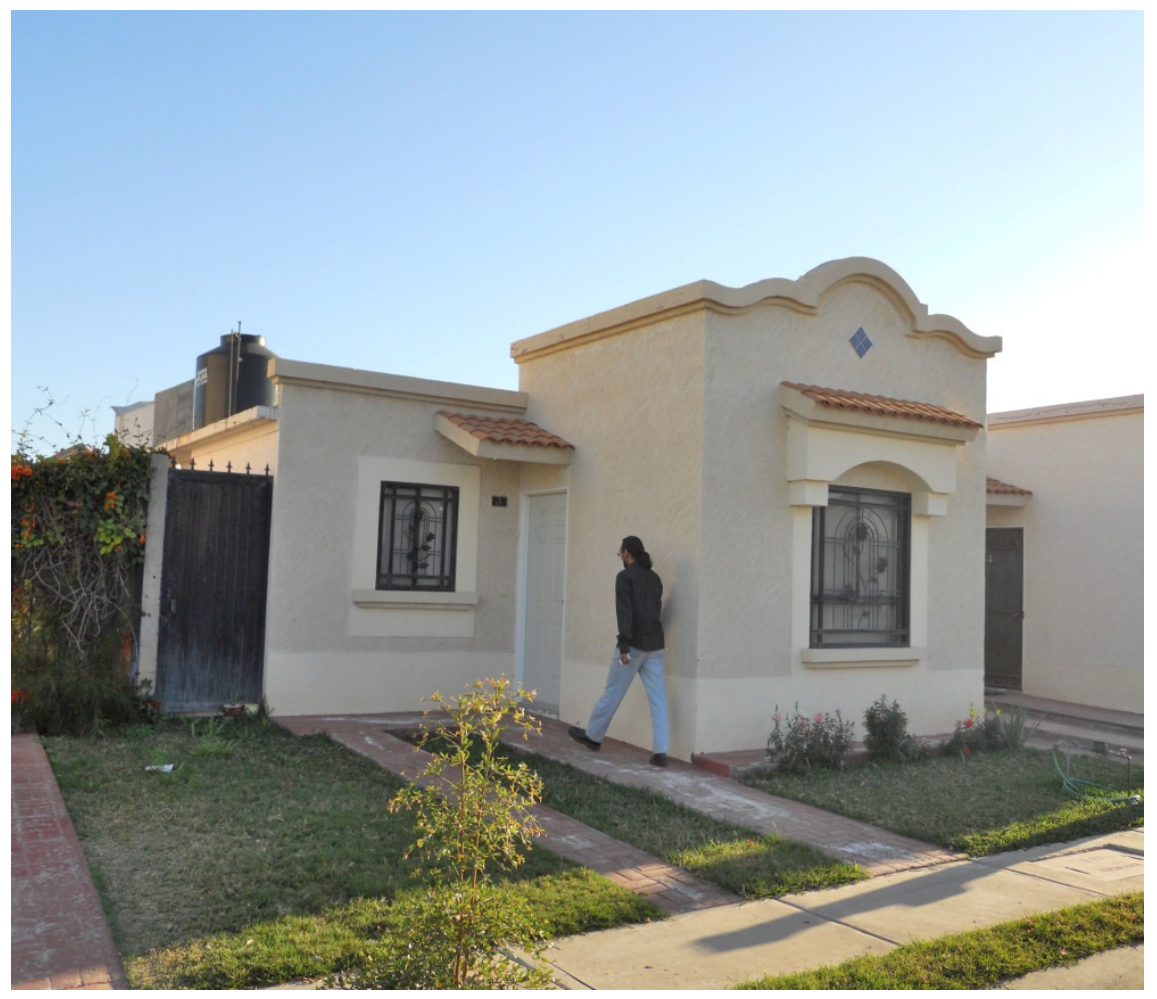

Figure 2: Main facade of a minimum house that was analysed.

A north-south orientation of the main elevation prevails in most units. Walls are made of concrete hollow blocks finished with latex paint generally in light colours. 
The roof system consists of precast beams and polystyrene panels that function as a framework for a thin layer of reinforced concrete that is poured on top. As a final finish the roof has a waterproof membrane of white elastomeric polymer with high reflectance, recommended for the plentiful solar radiation of the region.

None of the openings has any kind of solar protection or shading device. Regarding the exterior areas, in most cases the house does not have any paving material and it does not have any sunscreen or trees. In rare cases the inhabitants have modified these conditions, mainly because of economic restrictions.

Due to summer climatic conditions, most users utilize some kind of air conditioning system to ensure their comfort. The most commonly found is an evaporative cooler system, known locally as "cooler". This system is preferred over other air conditioning systems, because compared to an A/C unit, the "cooler" costs less and is mechanically simple to repair and maintain. Some disadvantages are that it requires the use of water to operate and does not work well in temperatures over $40^{\circ} \mathrm{C}$. In addition, when the highest temperatures occur, relative humidity increases because of the rainy season, decreasing the cooling effect.

There are also individual air conditioning systems that are installed in a window or wall opening, as well as mini-split air conditioners. These are usually located in the bedrooms, complemented by a regular fan, commonly found in the livingdining area.

Responding to the problem of high-energy consumption, people have come up with creative but ingenuous solutions, which are more or less effective and sometimes quite expensive in relation to the benefits they offer. For example: windows covered with polystyrene plates and aluminium foil or other reflective film; polyurethane applied copiously on walls and roofs, and in extreme cases doors and windows that are closed permanently.

Considering the extreme climate conditions, architectural design criteria must be adapted and applied stringently in order to minimize the negative climate effects on the occupants and their energy consumption.

\section{Proposal for a technical standard on bioclimatic construction}

Mexican laws aim to safeguard costs, quantities and characteristics in the design, production and service of consumer goods between entities and individuals, particularly those in widespread use and readily available to the public. There are two basic types of norms in Mexican law, the Mexican Official Standards (NOM, its acronym in Spanish) and the Mexican Standards (NMX, its acronym in Spanish). Only the NOM standards are mandatory, while the NMX standards only express a recommendation of parameters and procedures. If a NMX standard is mentioned as part of a NOM standard it becomes mandatory [2].

Since specifications and design recommendations are proposed in the field of urban and architectural design, as well as building spaces for human use, we propose a complementary technical standard to make this type of norm mandatory in Mexico, which must be integrated in the municipal regulation for construction. 
The municipal regulation dictates the minimum safety and habitability requirements for all buildings. The complete proposal of the standard, as well as other supporting documents can be viewed on the BAN website [3].

\subsection{General objective}

The Complementary Technical Standard on Bioclimatic Construction aims to reduce the environmental impact on construction, buildings and their usage by incorporating obligatory regulations that improve the efficiency of energy and habitability.

\subsection{Field of application}

This standard will be mandatory in the municipalities in which it is implemented. It will include a variety of activities for land developments and building constructions, and it will cover new projects, renovations and changes of use for buildings of public and private use, with the objective of improving human activities.

However, in certain circumstances the literal fulfillment of any section may be omitted, as long as justified technical reasons are submitted and accepted by the Municipality, in addition to taking compensatory measures to achieve the intended objective.

\subsection{Focus of the technical standard on bioclimatic construction}

The technical standard develops, in an articulated manner, a set of rules in three main areas related to building and urban space: efficient energy use; environmental comfort; vegetation with a low consumption of water in urban zones.

\subsubsection{Efficient energy use}

This approach includes urban and architectural planning and building based on bioclimatic criteria. Energy efficiency is achieved by two approaches: the use of advanced technology and efficient facility design in accordance with the Mexican Standards (NMX) and the Mexican Official Standards (NOM), and secondly through an efficient urban and architectural design that applies bioclimatic recommendations. All Mexican Standards related to energy issues are available on the website [4].

\subsubsection{Environmental comfort}

Environmental comfort refers to the conditions, both climatic and those generated by the interaction of people with the natural and built environment, which should be the appropriate ones for human performance of daily activities. Environmental comfort relates to thermo-hygrometric, visual and acoustic conditions.

\subsubsection{Vegetation with low water consumption in urban areas}

This section focuses on the use of vegetation associated with building and public spaces, enhancing its beneficial climatic effects and encouraging low water 
consumption. The proposal's information is based on the empirical background of the research group, as well as previous studies and project specifications.

\section{Content and structure of the technical standard on bioclimatic construction}

This technical standard consists of 16 items: 1 transient and 2 annexes, which are divided into 6 chapters.

\subsection{Chapter I: general considerations}

This chapter contains 4 articles that explain the content, objectives, scope and enforceability of the technical standard; general concepts essential to better understand the content.

\subsection{Chapter II: urban project considerations}

\subsubsection{Street design}

This article takes into account the main factors involved in urban design with a bioclimatic focus: ventilation, street and lots orientation, street layout, secondary streets and housing subdivision.

\subsubsection{Procedures to reduce the impact of the urban heat island}

In order to reduce overheating of urban areas, which promotes increased power consumption and thermal discomfort, the application of urban design procedures to mitigate the effect of the heat island on urban areas will be discussed. The following aspects will be covered: flooring and coatings; elements of artificial shading; urban vegetation.

\subsection{Chapter III: considerations for projects with bioclimatic building}

This chapter covers all aspects that should be considered to achieve projects that are more comfortable and energy efficient in the building process, by taking into account issues such as the shape, proportion and orientation of buildings in relation to the environment. This chapter includes 9 articles.

\subsubsection{Shape and compactness}

For isolated buildings or houses, the ideal plant shape is rectangular, with the largest axis oriented in the east-west direction exposing north and south façades. Compactness (C) should be as low possible. Compactness is defined as the ratio between the volume $\mathrm{V}\left(\mathrm{m}^{3}\right)$ by the thermal envelope content and the sum of the surfaces $\mathrm{S}\left(\mathrm{m}^{2}\right)$ of the envelope, according to the equation: $\mathrm{C}=\mathrm{V} / \mathrm{S}(\mathrm{m})$.

\subsubsection{Orientations}

It is mandatory to orient one of the main façades south or north (with a maximum deviation of $\pm 40^{\circ}$ ). Larger deviations will be accepted only in existing buildings 
and lots that inevitably constrain the orientation. Some measures should be implemented to reduce the drawbacks of excessive deviation regarding the optimal orientation.

\subsubsection{Thermal insulation}

This section refers to the maximum heat transfer indicated in the current Official Mexican Standards NOM-008-ENER-2012 [5] and NOM-020-ENER-2011 [6]. Recommendations will be made to determine the heat transfer by taking into account the heat capacity of building materials, and making calculations using a thermal simulation program.

\subsubsection{Openings and protections}

This article refers to the design and calculation of the openings and devices for the protection and delimitation of the gains from solar radiation suitable for each orientation and climatic region.

Recommendations will also be made for building design and materials, with the purpose of implementing devices capable of resisting the local climate characteristics (corrosion, UV radiation, dust, wind and pests).

The calculation of the sun protection factor and the maximum area of windows and skylights should be performed according to the proposals of the NOM-008ENER-200 [5] and NOM-020-ENER-2011 [6].

\subsubsection{Passive solar gain}

New buildings must include a quantitative assessment of winter solar gains, which will be achieved by means of passive solar systems. It is recommended that the solar collection devices take into account sun protection during the hot season.

\subsubsection{Natural lighting}

In addition to windows, overhead lighting will be considered as a way to get a uniform distribution of natural light.

The lighting provided by windows and skylights will provide the highest possible percentage of the requirements necessary to properly perform the activities meant for each area, which will then be complemented by artificial lighting devices.

\subsubsection{Ventilation}

It is mandatory that all buildings have the capability to allow crossed ventilation. In the cases where this is not possible, interior ventilation ducts will be used. Buildings for residential use with a unique exterior that don't allow crossed ventilation will not be accepted unless compensatory measures are taken to minimize adverse consequences on comfort and hygienic deficiencies due to ventilation. These measures must not add more power consumption and must be justified accordingly.

\subsubsection{Outdoor areas}

This article establishes that all public and private outdoor spaces, whether they are transient or permanent use areas, should be shaded during the season with the 
highest insolation, either with vegetation or other devices such as pergolas and sunshades, or a combination of both.

In outdoor parking spaces, at least $50 \%$ of the area must be shaded with a combination of sunshades and trees. Shadow projection must be calculated to ensure vehicle and user protection from the sun. Crosswalks with sun protection must also be provided to ensure comfortable movement of people within the outdoor parking space.

\section{Evaluation of the implementation of the technical standard}

To verify that the standard is accomplished, an evaluation form has been created. These forms contain the aspects that must be covered by each article and the required evidence, as well as the points awarded for its completion.

The points assigned to each aspect will be weighed according to the needs and particularities of each climatic region and the characteristics of each city where it is to be applied.

The evaluation system considers four possibilities in the evaluation:

○ Compliant;

- Partially compliant;

○ Does not comply;

- Not applicable.

To obtain the points from the criteria it is necessary to either be "compliant" or "not applicable", depending on the project. On cases with "not applicable", a technical study will be given with equivalent alternatives.

\section{Conclusions}

In the case of design and building construction for human use, each municipality is in charge of regulating aspects of design and construction related to the minimum hygro-thermal and lighting comfort, as well as the efficient use of energy, but is very poorly defined and there is no clear methodology available to evaluate them.

However, some initiatives include the publication of the Official Mexican Standards like NOM-008-ENER-2001 [5] and NOM-020-ENER-2011 [6] that regulate energy efficiency in non-residential buildings and housing but these standards only restrict heat transfer through the building envelope, given a limited number of design strategies, focusing almost exclusively on the thermal resistance of the building materials.

These emerging standards, along with others that regulate the manufacture of air conditioning equipment, luminaires and energy efficiency in outdoor lighting, are the beginning of specific energy legislation.

Unfortunately, there is a long way to go for the application of these regulations in Mexico. In a recently applied survey, only a small percentage of architects and civil engineers, of the total sample, knew or had heard of them and no one had put them into practice, despite some having been in operation for more than 10 years. 
On the other hand, its application is not mandatory until the regulations are reflected by the local building codes.

Aware of this need, the Bioclimatic Architecture Network has made a legislative proposal focusing on three main areas related to building and urban space: efficient energy use; environmental comfort; vegetation with low water consumption in urban spaces.

This proposal is made using the existing format for Supplementary Technical Standards, giving the proposal the possibility of joining the local building regulations in force without requiring major modifications.

Certainly, this is not enough, besides the proposal, it is necessary to implement a verification system, as well as training and professional development program so that stakeholders can apply it properly. This way, value will be added to projects and users will have comfortable buildings with reduced operating costs and an overall better quality of life.

\section{References}

[1] Marincic I, et al. La construccion actual de viviendas en Hermosillo y su adecuacion al clima por medios pasivos. In Memorias de la XXXV Reunion Nacional de Energia Solar, ANES, Chihuahua, Mexico. October 2011, pp. 189-193, 2011.

[2] Huerta O. Las Normas Oficiales Mexicanas en el ordenamiento jurídico mexicano. Boletín Mexicano de Derecho Comparado, Nr. 92, May-August, 1998. ISSN 0041 8633. Mexico. Online: http://www.juridicas.unam.mx /publica/rev/boletin/cont/92/art/art4.htm

[3] Red Temática de Arquitectura Bioclimática. Thematic Network on Bioclimatic Architecture website, Mexico: http://www.lema.arq.uson.mx $/ \mathrm{rab} /$

[4] National Commission for the Efficient Use of Energy (CONUEE) Official Mexican Standards on energy efficiency, online: http://www.conae.gob.mx /wb/CONAE/CONA_1002_nom_publicadas_vigen

[5] Secretaría de Energía. Official Mexican Standard NOM-008-ENER-2001, Energy efficiency in buildings, nonresidential building envelope. Diario Oficial, 25 de abril de 2001, segunda sección, 2001, Mexico.

[6] Secretaría de Energía. Official Mexican Standard NOM-020-ENER-2011, Energy efficiency in buildings, building envelope for residential use. Diario Oficial, 29 de agosto de 2011, primera sección, 2011, Mexico.

[7] Secretaría de Energía. Official Mexican Standard NOM-023-2010-ENER, Energy efficiency of air conditioners with a split system, test methods and labeling. Diario Oficial, 20 de diciembre de 2010, primera sección, 2010, México.

[8] Secretaría de Energía (2007, 06). Official Mexican Standard NOM-011-2006ENER, Energy efficiency of air conditioners with a central system, test methods and labeling. Diario Oficial, 22 de junio de 2007, primera sección, 2007, México. 